\title{
Untrustworthy subjects? Risks, blame and gradual prison release in Ukraine
}

European Journal of Criminology

(C) The Author(s) 2020

(c) (i) (\$)

Article reuse guidelines: sagepub.com/journals-permissions DOI: |0.I I77//4773708209606/3 journals.sagepub.com/home/euc

$\Theta$ SAGE

\author{
Anton Symkovych \\ University of Melbourne, Australia \\ University of Johannesburg, South Africa
}

\begin{abstract}
Penal authorities and society in general perceive prisoners as untrustworthy. Much of the administration of punishment constitutes the assessment and management of the risks that prisoners pose. In this article, I explain how Ukraine balances the noble goals of prisoner reintegration with an inherent mistrust of prisoners. Drawing on a semi-ethnographic study of a medium-security prison for men, I discuss how, in anticipation of their freedom, prisoners also calculate their perceived risks. Through examination of how prisoners assess their vulnerability to risky behaviour and opt out from gradual release, I argue that prisoners as well as the state often deem themselves untrustworthy subjects. Furthermore, I discuss the roles of the informal prisoner society and (paucity of) prison's rehabilitative efforts in prisoners' decisions concerning their transfer into semi-open conditions. I argue that, rather than being an alternative - and even a threat - to parole, gradual release, supported by rehabilitative and developmental programmes, constructive services and temporary leave schemes, should become a path to release, including release on parole. Prisoners and staff alike should not make an unfair and unconstructive choice between 'less risky' parole, because of its loose surveillance, and more failure prone (for prisoners) and blame risky (for staff) gradual release.
\end{abstract}

\section{Keywords}

Risk assessment, trust, blame, gradual release, open prison, Ukraine

\section{Introduction}

Most prisoners are eventually released. However, to move through their sentence prisoners are usually expected to demonstrate 'progress' in their 'rehabilitation', 'reform' or 'correction'. This is true in the 'West' but not exclusively so. Such 'rehabilitation' or 'correction' increasingly means 'reoffending risk reduction' and 'risk elimination' (Barry,

\section{Corresponding author:}

Anton Symkovych, School of Social and Political Sciences, University of Melbourne, Melbourne, Victoria 3010, Australia.

Email: anton.symkovych@unimelb.edu.au 
2019; Crewe, 2009; McKendy, 2006; Monahan and Skeem, 2016; Warr, 2020). In return, as a reward for their rehabilitative efforts (cynics would call this compliance), prison authorities may grant prisoners additional privileges, including transfer into a less restrictive custodial regime. I term this 'gradual release'. Gradual release is also intended to prepare prisoners for (re)integration into the wider community upon actual release (Grupp, 1970; United Nations, 2015: Rules 4 and 87). Indeed, Wright and Rosky (2011) argue that release without transitional preparation may account for the traditionally high post-prison recidivism rate (see Inciardi et al., 2004). Although one of the aims of imprisonment is to reduce reoffending, recidivism remains high across jurisdictions (Fazel and Wolf, 2015).

By virtue of keeping people in custody, the state shares responsibility for any potential harm caused by prisoners inside prison or outside if on temporary leave or in semi-open regimes (see Maiorano and Others v. Italy, 2009; Mastromatteo v. Italy, 2002). Breach of rules or laws by prisoners may cause public outcry, litigation against the state or, in the case of prison administrators, censure from superiors (Symkovych, 2020a; Wright and Rosky, 2011; see also Bartels et al., 2018). Hence, risk assessment, implicit or formalized, constitutes an indivisible part of the administration of prisoners' movement through the system.

Much of scholarship deals with the practical, actuarial side of risk assessment, although there has also been a surge in work addressing the moral and theoretical aspects of the risk-centred turn in penal management (Andrews et al., 1990; Barry, 2019; Bonta, 2007; Hannah-Moffat, 1999; Monahan and Skeem, 2016; Singh and Fazel, 2010; Turnbull and Hannah-Moffat, 2009). However, few scholars have examined how prisoners themselves perceive their risks. Thus, in this article, drawing on a semi-ethnographic study conducted in a medium-security prison for men in Ukraine, I examine how some prisoners assessed their vulnerability to risky behaviour and thence decided to opt out from gradual release. I demonstrate how, in anticipation of their freedom, prisoners assessed the perceived risks and benefits of gradual release against the seemingly less 'precarious' parole and purportedly less 'taxing' incarceration in the main prison. I argue that prisoners, as well as the state, often deem themselves untrustworthy subjects.

\section{Risks, trust and social reintegration}

Although individual prisons differ in their capacity to harm and destroy people or, conversely, help people to reinvent themselves and lead a law-abiding life upon release, prisons are generally not very successful in preventing harm. Research underscores that incarceration may actually be more criminogenic than deterrent (Cid, 2009; Listwan et al., 2013; Vieraitis et al., 2007). Even though reasons for reoffending are complex, often compound, conditional and dynamic, ${ }^{1}$ post-prison recidivism remains high in most countries (for example, Cullen et al., 2011; Fazel and Wolf, 2015; Gaum et al., 2006; Lievesley et al., 2018).

Regarding prison-related factors, research demonstrates that gradual transition back to the community while equipping prisoners with appropriate skills, social capital and self-image may prevent or delay reoffending (Genders and Player, 1995; LeClair and Guarino-Ghezzi, 1991; Liebling, 2004; Toch, 1967). This transition often entails a relaxation of custodial restrictions by allowing prisoners to interact with their family, attend 
educational and vocational courses or substance abuse treatment programmes, and work outside the prison walls (Cheliotis, 2008, 2009; Inciardi et al., 2004). It can take the form of a transfer to separate prison premises, as well as temporary leave, whereby prisoners return to prison every evening or after a brief period of out-of-prison purposeful activities (Gaum et al., 2006; Grupp, 1970; Knox and Humphrey, 1981; Shichor and Allen, 1978; Turner and Petersilia, 1996). Although some studies establish no evidence that such programmes reduce reoffending (Turner and Petersilia, 1996; Waldo and Chiricos, 1977), the absence of any form of transition makes law-abiding life upon release extremely difficult to achieve (Lievesley et al., 2018; Wright and Rosky, 2011). ${ }^{2}$

Managing prisoners often means weighing the tension between security and care, although these two aspects of custody are not exactly opposite (see Genders and Player, 1995). Administering punishment progressively prioritizes managing risks (Barry, 2019; Hannah-Moffat, 1999; Monahan and Skeem, 2016). The problem of trust looms large within the prison environment (Crewe, 2009; Liebling, 2004; Liebling and Arnold, 2012). Prison authorities often mistrust prisoners, whom they consider to be 'untrustworthy bodies' (Ugelvik, 2014). Prisoner transition through sentences, including the authorization of gradual release, predicates on the assessment of prisoners' risks (Crewe, 2009; Monahan and Skeem, 2016; Shammas, 2014). In most penal systems, this entails discretionary decisions that manage conflicting interests, concerns and rights. Most notably, official decision-makers must find a balance between threats to public safety (and the caprices of public opinion) and the merits of the offenders' progressive social reintegration (Alexander, 1986; Barry, 2019; Symkovych, 2020b). However, a more immediate concern for prison administrators is the fear of 'negative visibility' (Symkovych, 2020a): if prisoners in their care transgress the rules and this becomes known to higher authorities or the public, prison administrators are often chastised. To minimize such breaches, prison administrators assess the probability of prisoners bringing them into disrepute (for example, Cheliotis, 2005, 2008; Markley, 1973; Shichor and Allen, 1978). Prisoners are well aware that prison authorities distrust them. ${ }^{3}$ Being conscious of this mistrust, many prisoners assess the likelihood of approval for a more relaxed regime. This self-risk assessment sometimes results in prisoners deciding not to apply for programmes that are regarded as high risk by the authorities: for example, temporary prison leave (Cheliotis, 2005). Although different risk models used in assessing prisoners and their 'criminogenic needs' are proliferating through the literature, we still have little knowledge of how prisoners view and act on their own perceived risks. Furthermore, much of the Anglophone scholarship on penal risks and decision-making builds on research in the 'West'. In this context, I explore how prisoners in a Ukrainian men's prison evaluated the risks associated with their transfer into semi-open conditions as part of their gradual release. Before I proceed, I provide an overview of the Ukrainian prison system in flux, followed by an explanation of my methodology.

\section{Ukrainian prison system}

Ukraine has inherited from the Soviet Union a massive prison population along with over-restrictive penal policies and prison practices. Although many of those remain, the country is gradually liberalizing its prison regimes, increasing prisoner rights and 
drastically reducing prisoner numbers. The imprisonment rate has dropped from 398 prisoners per 100,000 general population in 2005 to about 142 in 2020 (Prison Portal of Donetsk Memorial, 2020). ${ }^{4}$ As a signatory to all major human rights instruments, Ukraine now allows national and supranational inspections of its prisons. Although these inspections acknowledge positive changes in policies and on the ground, they consistently reiterate the major problems that plague Ukrainian prisons: inadequate health care and high mortality, violence and abuse, understaffing, lack of purposeful activities, and unjustifiably punitive regimes, especially for remand and life prisoners (European Committee for the Prevention of Torture and Inhuman or Degrading Treatment or Punishment, 2015, 2017a, 2017b, 2018; Subcommittee on Prevention of Torture and other Cruel, Inhuman or Degrading Treatment or Punishment, 2006, 2007, 2014, 2017; see also Povoroznyy v Ukraine, 2020).

Out of Ukraine's almost 52,000 prisoners, about 37,000 have been sentenced, including 11,797 convicted of theft, 6989 of burglary and robbery, 6555 of murder, 2862 of grievous bodily assault, and 629 of rape (Prison Portal of Donetsk Memorial, 2020; Ukrainian Penitentiary Service, 2020). Even though in the wake of independence Ukraine has discovered early conditional release (parole) as a means of reducing, as well as controlling, its prison population (see Symkovych, 2018a, 2018c), the trend of early conditional release has turned downward in recent years. In 2019, only 4895 out of 13,109 who qualified were released early on parole ( 37.34 percent), compared with 37.80 percent in 2018, 38.22 percent in 2017, 41.15 percent in 2016, 47.2 percent in 2015 and 53.5 percent in 2014 (Prison Portal of Donetsk Memorial, 2020). Liberalization in Ukraine is neither even nor irreversible. The Ukrainian Penitentiary Service (UkrPS) ${ }^{5}$ remains a militarized, highly centralized organization that curtails local discretion. The culture of scapegoating and evasion of responsibility within the UkrPS is characteristic (see Symkovych, 2020a). Prisoners' security categorization has no individual risk assessment. The nature of the crime, rather than escape risks or control problems, determines the security classification. Prisoners generally serve sentences in their home regions, mostly in the prisons they were sent to upon conviction. Transfers to prisons of a different security level are rare and have to be authorized by the UkrPS Head Office (CriminalExecutive Code of Ukraine [CECU], 2003: Article 100).

One crucial vestige from the Soviet era, and the consequence of severe understaffing and legitimacy deficit, is the major role played by the prisoner underworld organization in sustaining order inside Ukrainian men's prisons. Without it, as I discuss elsewhere, prison administrators arguably could not maintain peace or the required industrial production. Thus, despite an official discourse of disapproval, the authorities accommodate and benefit from this co-governance model (see Symkovych, 2018a). Although it provides some stability and predictability, including by codifying and curbing violence, this system of informal justice and extra-legal governance tightens penal control and stratifies prisoners by institutionalizing inequality. Based on their reputation, performance at initial informal probes and tests, personal choice and subsequent conduct, prisoners occupy one of the four strata ('castes') of the informal hierarchy (Symkovych, 2018b, 2018d). This hierarchy forms the backbone of unofficial prisoner governance and operates through constant mutual surveillance with swift and harsh enforcement of its informal practical norms (Symkovych, 2017, 2018c). Ukrainian male prisoners must exercise 
constant extreme caution and self-censorship to maintain their status in this informal prisoner hierarchy: their quality of life, if not survival, depends on it. Failure to follow underworld rules and meet masculine expectations may result in relegation to the bottom of the informal hierarchy, with its attendant physical and symbolic ostracism and universal contempt. These masculine expectations include a measure of physical and psychological fortitude, along with some defiance of the formal authorities and official rules (see Symkovych, 2017, 2018c, 2018d for a detailed description of the normative foundation and practical operation of the Ukrainian informal prisoner sociality).

Officially, however, incarceration in Ukraine, apart from retribution and deterrence, serves to 'correct' ('rehabilitate') and re-socialize offenders (Criminal Code of Ukraine, 2001: Article 50). Ukraine employs a progressive model of imprisonment, whereby, once the authorities deem that a prisoner has, in official parlance, 'entered a path of correction', that is, demonstrated signs of being 'rehabilitated', they receive additional privileges and can request a transfer into a less restrictive regime or parole. Prisoners in minimum- and medium-security establishments can opt for gradual release. This constitutes transfer to a section outside the secure perimeter of a closed prison that, besides relaxing many custodial restrictions, may allow prisoners to leave prison during the day, to take two weeks' leave and, in some circumstances, to live in the vicinity outside the prison while de jure continuing their custodial sentences. In other words, at the policy level, Ukraine accepts the benefits of gradual release and institutionalizes its various forms. However, I demonstrate that entrenched mistrust of prisoners and prisoners' selfassessed risks often trump the ideal of offenders' rehabilitative gradual reintegration. I will expound this apparently counter-intuitive situation after outlining my methodology and the Ukrainian policies governing gradual release.

\section{The semi-ethnographic study}

My discussion draws on a semi-ethnographic study conducted in a medium-security prison for sentenced men in the Kyiv region of Ukraine. In January 2019, the prison housed 424 prisoners, including 23 prisoners in the detached pre-release sector (that is, 5.7 percent). This prison caters for recidivists, the majority of whom at that time (156) were convicted of theft. Other major offences included robbery (83), violent robbery (46), premeditated murder (29), premeditated grave bodily assault (28) and rape (8). Most men were serving sentences of three to five years (186) or five to eight years (116). Prisoners were generally young, with 188 prisoners aged between 30 and 40 years, followed by 109 prisoners aged 40 to 55 years. All but 10 were Ukrainian citizens.

The population in the pre-release sector had a similar composition to that in the main prison, except that there were no foreign or stateless prisoners or prisoners convicted of murder (although there was one prisoner convicted of a murder there in 2018). Among pre-release sector prisoners, six had been convicted of theft, four of robbery, three of violent robbery (розбій) and one of criminal hooliganism. The others' offences were not disclosed to me. Of these 23 prisoners, 13 had sentences of three to five years, 7 had five to eight years, and 3 had between two and three years.

The prison enjoyed the status of a UkrPS model institution, in which new practices were tested before being rolled out across all Ukrainian prisons. During five months of 
fieldwork, I spoke with most officers and managers and about a third of the prisoners, both in the main prison and in the attached pre-release sector. Additionally, I formally interviewed 21 officers and managers as well as 20 prisoners. As I detail elsewhere, the selected samples represented the overall diversity, in terms of their characteristics, as well as their experiences and opinions (for more information about the prison and data collection and analysis, see Symkovych, 2017, 2018a, 2018b, 2018d). These formal interviews, lasting from two to six hours, complemented the data collected through months of observation and informal conversations (Symkovych, 2019). Furthermore, as I lived in the UkrPS Training Academy during my fieldwork, I discussed my emerging findings and the situation in other Ukrainian prisons with prison officers from all across the country; they were there for several weeks for either initial or refresher training. Although the original themes centred on power relations, many more topics arose during our conversations, my observations and subsequent interviews - from the sub rosa economy to sex relations, informal prisoner stratification, the officers' views of their job and their managers, penal policies and practices. The thematic analysis of fieldwork data produced a wide array of themes, but here I draw only on those related to risk and gradual release.

\section{Gradual release}

Ukrainian law presents gradual release as a reward for prisoners' good behaviour, as a means of 'correction', and as a preparatory step to ultimate release. Once prisoners have served the minimum tariff required and demonstrated compliance and diligence, they may progress towards a transfer to pre-release sectors that are detached from the main prison secure area. These are officially called 'social rehabilitation' and 'social adaptation' sectors. ${ }^{6}$ Regimes in these pre-release sectors resemble those in minimum-security prisons with relaxed conditions and in open prisons ('correctional centres').

Minor prisoners can be moved to a 'social adaptation' sector if their release or parole date is within six months (Prison Bylaws, 2018: Rule XXX). Adult prisoners convicted of medium-gravity crimes can be moved to social rehabilitation sectors after serving a quarter of their custodial sentence. For those convicted of a premeditated grievous crime or those whose grievous crime was committed within a probation period following a comparable crime, the minimum tariff is a third of their sentence. Those convicted of especially grievous crime or reconvicted while on early release can be moved to social rehabilitation sectors if they have served at least half of their custodial sentence. Prisoners who meet these criteria but who have not undergone treatment for sexually transmitted diseases, active tuberculosis, drug and alcohol dependency, or psychiatric conditions are not allowed such transfers. Prisoners who have committed a premeditated crime while in an open prison or detention house are also barred (CECU, 2003: Article 101). These exclusions are intended to prioritize public safety.

Prisoners held in the pre-release sectors of minimum-security prisons with general conditions and those of medium-security prisons are permitted to keep mobile telephones and money, wear civilian clothing, have unlimited short visits as well as monthly one-to-three day family and conjugal visits (CECU, 2003: Articles 59 and 99). Only prisoners in prerelease sectors and open prisons can request temporary prison leave (Symkovych, 2020b). Additionally, after serving one month in the pre-release sector, these prisoners can be 
employed outside prison establishments and may be authorized for unsupervised movement. Furthermore, after serving at least six months and demonstrating compliance with prison rules, prisoners in these categories may be allowed to move into private accommodation with their families, provided this is within the prison's village or town and they report to the correctional centre several times a week. Women prisoners relieved from work because of pregnancy and those with children under three years old can be authorized by a Prison Commander, in consultation with an overseeing commission, to reside outside prison, provided they are not convicted of grave offences and their sentences are under five years. These prisoners can wear civilian clothing and have money and mobile telephones. They must report weekly (Prison Bylaws, 2018: Rules XXIX-XXXI).

Thus, in line with the international evidence that points to the benefits of gradual release, Ukrainian law institutionalizes a progressive system of punishment that theoretically allows prisoners gradual transition from a closed prison regime to ultimate freedom. However, the number of prisoners in Ukraine who benefit from gradual release remains relatively low. In 2018, only 10 minor prisoners were transferred to pre-release sectors. On 1 September 2018, out of 1643 men and 1532 women housed in minimumsecurity prisons, only 164 prisoners, or 5.17 percent, were in the prisons' pre-release sectors. The pre-release sectors of medium-security prisons housed 102 women and 1092 men, and the total prison population of this category was 25,891 men and 19 women. ${ }^{7}$ In other words, only a small fraction of Ukrainian prisoners, approximately 5 percent, had the option of gradual release, so that most prisoners were released with no transition. ${ }^{8}$ In what follows, I provide a glimpse into prisoner and administrator decisionmaking and discuss the factors that potentially impede the appeal of gradual release.

\section{The pitfalls of gradual release in Ukraine}

Although all the prisoners with whom I spoke aspired to be released and many complained about the rigidity and pressure of the informal prisoner society (see Symkovych, 2018b, 2018c, 2018d), many sounded ambivalent about the gradual release scheme. So did case-manager officers (squad supervisors) and senior managers. This was because prisoners and staff deliberately weighed the risks and benefits. In their assessments, risks often exceeded the benefits of the pre-release sector.

\section{Risks through prisoner eyes}

Among the pre-release sector's benefits, prisoners mentioned living with far fewer people and having extra privileges. As we know, the insecurity and stress bred by the prison's compressed social environment along with the loss of autonomy and desirable goods constitute the classic 'pains of imprisonment' (Sykes, 1958). The prisoners in the pre-release sector appreciated living with only several other prisoners in contrast to the busy barracks with bunk beds in the main prison. Additionally, they no longer spent long periods queuing for headcounts and several brisk searches daily. Despite a less regimented and less crowded life, other privileges - and arguably important steps toward restoration to civilian life - such as temporary leave or unsupervised movement outside the prison's immediate vicinity were rarely, if ever, mentioned. Even though the reviewed 
studies highlight the benefits of these forms of gradual release and their role in resocialization, in 2017 and 2018 no pre-release-category prisoner in the research prison was granted temporary leave, unsupervised movement outside, or the right to reside with their family outside the prison. ${ }^{9}$ Whereas the authorities attributed this to the absence of prisoners' requests, I argue that, being conscious of their miniscule chance of having such privileges, prisoners did not bother to apply (see Cheliotis, 2008; Cohen and Taylor, 1972; Symkovych, 2020b). Transfers to the pre-release sector themselves already appeared to be a losing gamble. In 2018, out of 179 applications the prison authorities refused 155 transfers (303 applications/282 refusals in 2017 and 344 applications/325 refusals in 2016). ${ }^{10}$ The main reasons for rejection were the prisoners' 'inadequate degree of correction (i.e. rehabilitation)' or outstanding fines for disciplinary misconduct.

Although the prisoners in the pre-release sector appreciated the more relaxed regime, many in the main prison maintained that this easing was superficial (see Shammas, 2014). They argued that, if they opted for a transfer to the pre-release sector, they would be under greater scrutiny and harsher penal power than in the main prison because of the elevated risks of negative visibility (see also McNeil, 2018) - this, despite only one officer's presence in the pre-release sector. The regime's tightness (Crewe, 2009) lay not in direct supervision but in the risks that rule infringement entailed. First, because of critical understaffing, disciplinary power in the main prison operated more through intelligence and coercion than through direct supervision and immediate rule-enforcement (see Symkovych, 2018a). Second, as I detail elsewhere, the regime tightness in Ukrainian men's prisons is two-fold. Prisoners must navigate the demands, scrutiny and power of both the official controls and, perhaps even more pervasive, those of the underworld (see Symkovych, 2018c, 2018d). As one of the prisoners explained, this, together with being uprooted from a settled life, decreased the appeal of transfer into the pre-release sector:

Perhaps it won't make sense to you, but the greatest freedom is in prison [original emphasis]. You are settled here, you sleep tight. You've carved your little world, you've created your comfortable microcosm . . . In the [pre-release sector] there is ersatz [pseudo] freedom: they have you on a hook. A small incident - and you are back [in the main prison]. And once you are back you can forget about [getting] parole or amnesty [because you have violated the conditions]. They [officers] know this and they really get you, there is bullying [didovshchýna], you can't say, 'I am not going to do this or that'; they can even assign an outcast [prisoner'untouchable' in the informal prisoner hierarchy] to sleep next to you. They will tell you, 'You are all citizens of the united country' [sarcastically], they level the entire pyramid [of informal stratification] that has been erected [by prisoners] over years. (Prisoner)

This quotation highlights two risks. First, the risks of failure seemed higher than in the main prison where the authorities often overlooked minor and moderate transgressions. Prisoners there had collective bargaining power in the negotiated order (Symkovych, 2018a). Conversely, prisoners in the pre-release sector were on their own, exposed, with far-reaching sanctions. Although many of my research participants insisted that they had matured (see Symkovych, 2018b), most were critical of the prison's rehabilitative potential; even more of the mostly absent programmes - in the main prison and in the prerelease sector alike (see Crewe, 2009; Shammas, 2014). For example, most prisoners and staff recognized drug and alcohol use as an important part in offending. The anecdotes, 
often substantiated by prisoner cases I reviewed, about prisoners stealing to support a drug habit or killing a neighbour in a drunken brawl were ubiquitous. Although many prisoners were resigned to the idea that prison operated as a temporary human warehouse, some prisoners and staff felt indignant about the lack of programmes, as expressed by this interviewee:

[Prisoners] get fit [in here], then they are released, they get back to drugs for a year or two, then they are back in prison, get [fed and recuperate] here and so on. It's a disgrace. You [should] either send them to some isolated island where they can live, die or kill each other - whatever, or you treat them. (Prisoner)

In many cases, courts specifically ordered substance abuse treatment, but such programmes were non-existent. The closest to substance abuse treatment I once observed was a lecture by a case manager who told the prisoners that 'drugs are bad'. The officers from other prisons with whom I lived in the Training Academy during my fieldwork confirmed that this situation was typical across Ukraine. Because substance abuse and dependency remained largely unaddressed during sentencing, the prisoners appeared acutely aware of the risks that semi-open conditions posed:

You know, first, they transfer mostly the old and those without family into the settlement [to minimize escape risks]. ${ }^{11}$ Perhaps [also] out of pity. And these guys really suffer there because they are, let's be honest, mostly alcoholics. Some request a transfer just to finally fill, I mean, literally fill their throats with proper vodka and not that shit of wood stain [which they get illegally in the prison furniture workshop] . . . They know, and are reminded every day, that if they get drunk, they are fucked. They know it, but on the other hand they are free to walk around, the store where they sell vodka is right there, so I don't really want to be in their shoes, to be honest. To be frank, I would probably have gotten drunk and fucked my release and future. [Besides,] where can they hide? Everyone in the neighbourhood knows them and will [probably] betray them to the [prison] administration. They are on display [like on the palm of your hand]. It's not like when you are on parole and can drink all day long and no one will know. No one will actually even care [if you drink once you are on parole]. (Prisoner)

Second, apart from the immediate risk of succumbing to the temptations of free life and the higher probability of being detected and punished (unlike in the main prison), prisoners in the pre-release sector feared the long-term consequences. Staff and prisoners cynically expected that the majority of prisoners would be back very soon - and not without grounds considering the enormous challenges of post-prison life and the way the Ukrainian criminal justice system works (see Symkovych, 2018a; also Barry, 2019; Halushka, 2020). Being back, either through immediate failure or later because of reoffending, a male prisoner risks losing his hitherto carefully earned masculine status and faces the daunting prospect of being relegated to the lowest echelon of the informal prisoner hierarchy, hence a miserable life of ostracism, humiliation and dehumanization (see Symkovych, 2017). Although the informal prisoner norms increasingly value prudent balancing between the administration and the underworld over oppositional masculinity, many prisoners still perceived those who requested transfers as submitting to the formal authorities, thus being 'lesser' men. Such a reputation follows prisoners regardless of distance or time passed (see Symkovych, 2018b, 2018d). 
Despite relying very much on the underworld, the formal prison authorities, perhaps for ideological reasons, ${ }^{12}$ often required a public display of total submission from those prisoners to whom they granted parole or gradual release. Such prisoners had to sign a memorandum declaring their 'genuine willingness to leave their criminal life behind' and their gratitude to the administration for its trust (za výkazanu doviru). The prisoners often had to read this statement aloud from the parapet facing the especially assembled prisoner population to hear it. Some prisoners in the audience expressed sympathy because it was clear that such a palpably humiliating act was a prerequisite for freedom. Others despised such 'weakness' and 'unmasculine' submission. The formal authorities justified the practice, arguing that it helped to 'save' prisoners from 'relapsing':

I don't think there is anything wrong. Look, it's his choice, he could refuse; some do refuse. But if he gave his word to the Commander that he is not going back, if he made it public, he's burnt all his bridges, so to speak, there's no retreat. Is it bad? That's how it is. It's a sort of a tug-ofwar: either the underworld or us. If we pull a prisoner from their grasp, when he publicly rejects it, he'll think twice next time before transgressing. And if he's back [in prison], he won't be the criminal elite [that is, in the upper stratum of the informal hierarchy], because prisoners would remember this statement. (Deputy Commander)

Although the reputation-based prisoner 'society' would remember such a public submission, a noticeboard on the parade ground titled 'Those who do not keep their word' displayed the names of relapsed prisoners who had reoffended after signing such memoranda. What could further undermine a prisoner's informal status if they returned to the main prison after a stint in the pre-release sector was their proximity to prisoners from the bottom of the underworld pecking order - 'outcasts'. The informal norms prohibited close contact with these ostracized prisoners. Whereas in the main prison 'outcasts' were kept at a distance (with the administration's express connivance), such distancing was difficult in the small pre-release sector. Thus, a returnee was unlikely to enjoy a bona fide masculine status because of the suspicion of being 'contaminated' and thus 'emasculated' by an 'outcast', if one was residing in the pre-release sector at the same time, from touching them or their cutlery (see Symkovych, 2017, 2018b). Furthermore, the prisoners argued that, by accepting such transfers, prisoners were indebted to the administration and thus more controlled without room for manoeuvre or retreat. Guided by the principles 'if they can give you something - they can just as easily take it from you' and 'never say "I want" in prison' [so as not to give leverage against you], these prisoners fought to keep their distance and avoid alignment with or dependency on staff. In 2018, 13 prisoners officially refused a transfer to the pre-release sector (22 in 2017 and 19 in 2016).

Moreover, prisoners in effect had to gamble between applying for either a transfer to the pre-release centre or parole. Confronted with such a stark choice, the prisoners, weighing the risks and returns, tended to favour parole:

You know why most prisoners refuse to move to the settlement [pre-release sector]? It's because, once they do it, it counts as they have used their privileges (льгота), [effectively] cancelling the possibility of parole. No person in their right mind would do that [when] you can get 2-4 years behind [that is, early release on parole]. Not only that. If you fuck up when you are in the settlement, next time [you are in prison] you won't get parole [because of this]. It's 
not worth endangering parole for this [that is, for gradual release]. Pure arithmetic and common sense. (Prisoner)

Apart from such strategic thinking, including being realistic about their chances of reconviction, some prisoners weighed the temptations that freedom offers, together with their increased visibility and graver consequences of rule violation, against parole. In addition to being informed upon, these prisoners, in contrast to those in the main prison with its vast industrial zone, stood a higher chance of being observed by visitors entering the main prison or by the commanders and staff. This was because staff often congregated next to the sector entrance after lunch in the adjacent officer cafeteria or after meetings in the administrative building. In 2018, five prisoners were transferred from the pre-release sector back to the main prison because of regime violations such as possession of unauthorized articles or alcohol consumption (although none in 2016 and four in 2017). These failures in effect meant loss of early release on parole.

\section{Risks through staff eyes}

Although some officers and managers in my study expressed quite punitive views, including the need to use harsher punishments and re-introduce the death penalty (for example, Symkovych, 2019), none was against the gradual release scheme in principle. Furthermore, several officers believed that, once a prisoner is transferred, he decreases his allegiance to the informal prisoner society, or, as several officers said, has 'burned the bridges' with the underworld. Many officers recognized that imprisonment infantilized prisoners and to function in society they had to (re)learn self-reliance, self-control and responsibility. When discussing parole, some officers argued that prison should release prisoners early so 'they can help their mothers to plant potatoes', meaning be productive and useful rather than lingering in prison.

However, like the prisoners themselves, managers and officers perceived prisoners as too vulnerable to risks, especially in relation to alcohol and drugs. Ironically, although recognizing the need for prisoners to take responsibility and become less dependent, the staff were not ready to take responsibility and expose themselves to any potential blame:

In theory, it makes sense to let them [prisoners] be more free [move to a semi-custodial setting], even let them go home for a couple of days before granting parole, so they get used to not being controlled and use their own head. But it's asking for trouble. If they mess up on parole, it's their problem. They'd get extra time, they won't get [parole] again. But that won't really concern us. But if they do something stupid [while still officially attached to the prison], even just being caught by the cops when drunk - and of course the first thing they gonna do is get pissed - we all are in shit. [Questions will be asked, such as] Why we let them out? The Commander will be in trouble, in big trouble, I will be totally fucked [póvny pizdéts] because I've supported [gradual release on behalf of a prisoner], because I haven't ensured that the prisoner has [mimics the official parlance] 'entered the solid path of correction'. No one needs this and no one is going to put his neck on the line [just to lose a bonus, promotion or get reprimanded]. (Officer - personal case manager)

This quotation reflected the feeling of most officers with the power to recommend or approve transfers. Whereas officers unsurprisingly perceived prisoners as untrustworthy 
and prone to poor choices, the scapegoating culture entails this evasion of responsibility (see Symkovych, 2020a) and diminished their support for gradual release. What became evident was that the prison did little to address prisoners' 'criminogenic needs'. Both staff and prisoners recognized that imprisonment in its current form did not reduce risks and potentially amplified them, as with the case of enforced abstinence without treatment for substance abuse. Being realistic about prisoner propensity for risky behaviour and the resultant censure from superiors, the administration rarely granted gradual release.

To summarize, whereas much of the literature highlights how state agencies and their street-level bureaucrats assess the risks related to temporary and early release, such practices by prisoners are poorly documented. Even so, the current limited examination of prisoner decision-making echoes findings elsewhere that prisoners sometimes selfexclude from temporary and gradual release. They do this to minimize turmoil and the temptations of freedom, as well as to not jeopardize early release (Barry, 2019; Cheliotis, 2008; Cohen and Taylor, 1972; King and Elliott, 1977; Shammas, 2014). My study also furnishes evidence that the higher stakes that gradual release entailed - in increased visibility, tighter penal regime and the pervasive detrimental effect of the informal prisoner society - diminished its appeal to prisoners.

\section{Conclusions}

Imprisonment, at least in the 'West', increasingly centres on identifying and reducing prisoner risks. However, the literature lacks prisoners' endogenous perspectives regarding their sensitivity to those risks. My objective was to supplement the rich scholarship on authorities' assessment of the risks posed by prisoners by adding a glimpse into the logic of prisoner decision-making about gradual release and their own risk assessment by using a case study in a men's medium-security prison in Ukraine.

Although the extant literature advances the need for gradual reintegration into the community, only a tiny number of prisoners in Ukraine, around 5 percent, participate in gradual release schemes. Through the analysis of interviews with prisoners and staff in this explorative study, I aimed to identify potential reasons for this situation. The analysis identified that staff and prisoners alike deemed gradual release to be too risky.

For prisoners, the risks fell into three main categories. First, they believed that incarceration did not reduce their risks. Rehabilitative programmes in Ukrainian prisons are too basic, if present at all. Temporary incapacitation, including (relative) drug and alcohol abstinence, did not prepare the prisoners for the challenges that semi-open custodial conditions and eventual freedom presented. Second, and related to the first, perhaps counterintuitively the prisoners regarded the penal regime in the pre-release sector as tighter than that in the main prison. Their increased visibility, combined with a propensity for risky behaviour, increased their chances of failure. Third, and related to the second, the consequences of failure were far-reaching. Return to the main prison population jeopardized prisoner standing in the informal prisoner society and thus the subsequent quality of prison life. Additionally, violating the pre-release sector regime in effect deprived prisoners from seeking parole or another chance of gradual release in the future. As a result, prisoners preferred to seek parole. For them, parole constituted a less risky, thus preferential, option. Unlike elsewhere (see Barry, 2019; McNeil, 2018), parole in Ukraine involves 
limited aftercare and support, but, with its cursory supervision and scrutiny, it minimizes the chances of re-incarceration - contra placement in pre-release sectors.

For the prison authorities, the risks of gradual release were prohibitively costly. Although accepting in principle the need for offenders' gradual (re)integration into the community, the authorities were realistic about the prisoners' chances of failure. They recognized both their human fallibility and, perhaps implicitly, the prison's failure to reduce prisoners' chances of re-incarceration. Among the reasons for decision-makers being careful and conservative when relaxing custodial restrictions for prisoners, the research often cites authorities' consideration of public safety and the media outcry when prisoners breach their licence conditions. However, the officers and managers in my study appeared to be apprehensive only about their superiors' reaction and personal repercussions. This is perhaps not surprising given the scapegoating culture (Symkovych, 2020a). Rather than being concerned with prisoners desisting from crime or public safety, prison staff in my study clearly appeared preoccupied with being blamed for licence breaches or recidivism - preferring it to be applied elsewhere, even to their colleagues in the probation service. However, because it was a medium-security prison housing recidivists, this potentially led to cynicism, if not defeatism, for its prisoners and staff.

Although this case study of a single, model institution precludes generalization, this research highlights certain policy implications. First, the prisoners and staff in the research prison, and those officers in the Training Academy from across Ukraine with whom I lived for five months, almost universally agreed that prisoner drug and alcohol abuse contributed considerably to offending and incarceration. Not only should more non-custodial measures be applied to low-level offenders, but substantial substance abuse treatment, in prison and as a part of gradual release and parole, should be institutionalized. If Ukrainian prisons were ever to change from merely warehousing prisoners, considerable resources and knowledge must be invested in its personnel, programmes and regimes. Second, rather than being an alternative - and even a threat - to parole, gradual release, supported by rehabilitative and developmental programmes, constructive services and temporary leave schemes, should become the path to release. This support should extend to parole, perhaps at much earlier stages of custodial sentences. Prisoners and staff alike should not make this unfair and unconstructive choice between 'less risky' parole because of its loose surveillance and more failure-prone (for prisoners) and blame-risky (for staff) gradual release.

These findings, albeit limited, highlight how blame evasion, with its corresponding risk aversion, reduces support for gradual release. However, the European Court of Human Rights stresses that the avoidance of risk must have limits in a democratic society and that the member states' positive obligation to ensure public safety should not 'impose an impossible or disproportionate burden on the authorities' (Mastromatteo v. Italy, 2002: para 68). The court's reminder in the cited case that human conduct is prone to unpredictability hardly seems reassuring to prison officials responsible for decisions concerning the relaxation of custodial regimes (see Alexander, 1986; Barry, 2019). The de facto 'one strike - and you are out' policy abhors the very possibility of personal change. Human nature and inherently flawed risk assessment preclude investing prison decision-makers with precision, objectivity, certainty and predictive ability - thus exposing them to unjustifiable blame. If imprisonment is meant to serve more than punishment 
and temporary incapacitation, a degree of risk, and trust, should be explicitly acknowledged and accommodated at policy level and through changing the institutional culture. Blame should not trump justifiable risk.

Notwithstanding its limitations, this case study remains one of the few efforts to examine how prisoners in the former communist bloc assess their own risks of re-incarceration. It adds to the growing non-'Western' criminological literature, which can only broaden our theoretical understanding of punishment by incarceration. The study complements the research done in the 'West' that highlights that releasing prisoners without equipping and supporting them is risky and likely to lead to re-incarceration. What I observed and what my respondents told me suggest that the Ukrainian prison functions primarily to punish and incapacitate. Many risks that the prisoners identified could, and should, have been reduced at the outset of their sentence rather than preventing them from progressing towards release.

\section{Acknowledgements}

I am immensely grateful to all my research participants for their time and for sharing their thoughts and experiences. I thank Dr Margaret Wilson for her continuous kind support.

\section{Funding}

The author(s) received no financial support for the research, authorship, and/or publication of this article.

\section{ORCID iD}

Anton Symkovych iD https://orcid.org/0000-0001-8477-5783

\section{Notes}

1. See Monahan and Skeem (2016) on variable risk factors and casual risk factors versus fixed and variable markers as regards 'criminogenic needs', promotive factors, and treatment potential.

2. See also Castellano and Soderstrom (1997) and Shammas (2014) on the 'pains of freedom' and pre-liberation anxiety and depression.

3. This distrust is mutual (Kauffman, 1988; Liebling, 2004; Mathiesen, 1965). The rise of routine risk assessment tends to further erode trust (Alexander, 1986; Crewe, 2009).

4. The numbers the Ukrainian Penitentiary Service publishes or supplies in response to freedom-of-information requests often do not add up, thus raising concerns about their reliability (see Prison Portal of Donetsk Memorial, 2020). Additionally, apart from losing control over territories with a significant population in Crimea and in the East in the wake of Russian military aggression, Ukraine has failed to conduct a comprehensive census since 2001.

5. Officially, the State Criminal-Executive Service is a department within the Ministry of Justice responsible for remand imprisonment and the execution of all criminal punishments, including incarceration and probation.

6. 'Social adaptation sectors' are attached to young offenders' institutions, whereas pre-release sectors in minimum- and medium-security prisons are called 'social rehabilitation sectors'. These sectors, informally called settlements (посёлок in Russian) in reference to the now obsolete punishment of exile, officially constitute a part of a prison, but often they are located outside the secure perimeter and prisoners there do not associate with the general prison population. 
7. The UkrPS supplied these statistics in response to my freedom-of-information enquiry. See note 4.

8. In $2017,17,681$ sentenced prisoners were released, including 2705 who were released early on conditional licence (parole), although 7317 sentenced prisoners met the minimum criteria for early conditional release. In 2018, 151 prisoners were transferred from maximum- to medium-security prisons and 41 prisoners were transferred from medium- to minimum-security prisons.

9. Even so, during the fieldwork, several prisoners were mending the roof above the main administrative building facing the pre-release sector and some worked on the refurbishment of the adjacent prison's store, thus enjoying a measure of 'freedom'.

10. The prison's shrinking population can partially explain the decline in the number of transfer requests. The prison housed 866 prisoners in 2011, but the number fell to 650 in 2018 and 424 in 2019. This trend reflects the decreasing national prison population in those years.

11. However, on 1 January 2019, out of 23 prisoners in the pre-release sector, 11 were between 30 and 40 years old, 3 between 20 and 30 years old, and 9 between 40 and 55 years old, thus reflecting the age distribution in the main prison.

12. See Crewe (2009) on authoritarian paternalism.

\section{References}

Alexander J (1986) Classification objectives and practices. Crime and Delinquency 32(3): 323-338.

Andrews DA, Bonta J and Hoge RD (1990) Classification for effective rehabilitation. Criminal Justice and Behavior 17(1): 19-52.

Barry M (2019) 'Walking on ice': The future of parole in a risk-obsessed society. Theoretical Criminology. First published online: 14 October 2019, https://doi. org/10.1177/1362480619880555.

Bartels L et al. (2018) Bail, risk and law reform: A review of bail legislation across Australia. Criminal Law Journal 42(2): 91-107.

Bonta J (2007) Offender risk assessment and sentencing. Canadian Journal of Criminology and Criminal Justice 49(4): 519-529.

Castellano TC and Soderstrom IR (1997) Self-esteem, depression, and anxiety evidenced by a prison inmate sample: Interrelationships and consequences for prison programming. Prison Journal 77(3): 259-280.

Cheliotis LK (2005) The prison furlough programme in Greece: Findings from a research project in the male prison of Korydallos. Punishment and Society 7(2): 201-215.

Cheliotis LK (2008) Reconsidering the effectiveness of temporary release: A systematic review. Aggression and Violent Behavior 13(3): 153-168.

Cheliotis LK (2009) Before the next storm: Some evidence-based reminders about temporary release. International Journal of Offender Therapy and Comparative Criminology 53(4): $420-432$.

Cid J (2009) Is imprisonment criminogenic? European Journal of Criminology 6(6): 459-480.

Cohen S and Taylor L (1972) Psychological Survival: The Experience of Long-term Imprisonment. Harmondsworth: Penguin.

Crewe B (2009) The Prisoner Society. Oxford: Oxford University Press.

Criminal Code of Ukraine (2001) No 2341-iii, 05.04.2001. URL (accessed 7 September 2020): https://zakon.rada.gov.ua/go/2341-14.

Criminal-Executive Code of Ukraine (2003) No 1129-iv, 11.07.2003. URL (accessed 7 September 2020): https://zakon.rada.gov.ua/go/1129-15.

Cullen FT, Jonson CL and Nagin DS (2011) Prisons do not reduce recidivism: The high cost of ignoring science. Prison Journal 91(3): 48S-65S. 
European Committee for the Prevention of Torture and Inhuman or Degrading Treatment or Punishment (2015) Report to the Ukrainian Government on the visit to Ukraine carried out by the European Committee for the Prevention of Torture and Inhuman or Degrading Treatment or Punishment (CPT) from 9 to 16 September 2014. CPT/Inf (2015) 21, 29 April 2015. URL (accessed 7 September 2020): https://rm.coe.int/16806985fd.

European Committee for the Prevention of Torture and Inhuman or Degrading Treatment or Punishment (2017a) Report to the Ukrainian Government on the visit to Ukraine carried out by the European Committee for the Prevention of Torture and Inhuman or Degrading Treatment or Punishment (CPT) from 21 to 30 November 2016. CPT/Inf (2017) 15, 19 June 2017. URL (accessed 7 September 2020): https://rm.coe.int/pdf/1680727930.

European Committee for the Prevention of Torture and Inhuman or Degrading Treatment or Punishment (2017b) Response of the Ukrainian Government to the report of the European Committee for the Prevention of Torture and Inhuman or Degrading Treatment or Punishment (CPT) on its visit to Ukraine from 21 to 30 November 2016. CPT/Inf (2017) 19, 27 July 2017. URL (accessed 7 September 2020): https://rm.coe.int/pdf/1680734be7.

European Committee for the Prevention of Torture and Inhuman or Degrading Treatment or Punishment (2018) Report to the Ukrainian Government on the visit to Ukraine carried out by the European Committee for the Prevention of Torture and Inhuman or Degrading Treatment or Punishment (CPT) from 8 to 21 December 2017. CPT/Inf (2018) 41, 6 September 2018. URL (accessed 7 September 2020): https://rm.coe.int/16808d2c2a.

Fazel S and Wolf A (2015) A systematic review of criminal recidivism rates worldwide: Current difficulties and recommendations for best practice. PLOS ONE 10(6): e0130390.

Gaum G, Hoffman S and Venter JH (2006) Factors that influence adult recidivism: An exploratory study in Pollsmoor prison. South African Journal of Psychology 36(2): 407-424.

Genders E and Player E (1995) Grendon: A Study of a Therapeutic Prison. Oxford: Clarendon Press.

Grupp SE (1970) Work furlough and punishment theory. Criminology 8(1): 63-79.

Halushka JM (2020) The runaround: Punishment, welfare, and poverty survival after prison. Social Problems 67(2): 233-250.

Hannah-Moffat K (1999) Moral agent or actuarial subject: Risk and Canadian women's imprisonment. Theoretical Criminology 3(1): 71-94.

Inciardi JA, Martin SS and Butzin CA (2004) Five-year outcomes of therapeutic community treatment of drug-involved offenders after release from prison. Crime and Delinquency 50(1): $88-107$.

Kauffman K (1988) Prison Officers and Their World. Cambridge, MA: Harvard University Press.

King RD and Elliott KW (1977) Albany: Birth of a Prison - End of an Era. London: Routledge \& Kegan Paul.

Knox WE and Humphrey JA (1981) The granting of work release. Criminal Justice and Behavior 8(1): 55-77.

LeClair DP and Guarino-Ghezzi S (1991) Does incapacitation guarantee public safety? Lessons from the Massachusetts furlough and prerelease programs. Justice Quarterly 8(1): 10-36.

Liebling A (2004) Prisons and Their Moral Performance: A Study of Values, Quality, and Prison Life. Oxford: Oxford University Press.

Liebling A and Arnold H (2012) Social relationships between prisoners in a maximum security prison: Violence, faith, and the declining nature of trust. Journal of Criminal Justice 40(5): 413-424.

Lievesley R, Winder B, Norman C and Banyard P (2018) A life sentence in installments: A qualitative analysis of repeat offending among short-sentenced offenders. Victims and Offenders 13(3): 409-426. 
Listwan SJ, Sullivan CJ, Agnew R, Cullen FT and Colvin M (2013) The pains of imprisonment revisited: The impact of strain on inmate recidivism. Justice Quarterly 30(1): 144-168.

Maiorano and Others v. Italy (2009) European Court of Human Rights case No 28634/06. URL (accessed 7 September 2020): http://hudoc.echr.coe.int/eng?i=001-96266.

Mastromatteo v. Italy (2002) European Court of Human Rights case No 37703/97. URL (accessed 7 September 2020): http://hudoc.echr.coe.int/eng?i=001-60707.

McKendy JP (2006) 'I'm very careful about that': Narrative and agency of men in prison. Discourse and Society 17(4): 473-502.

McNeil F (2018) Pervasive Punishment: Making Sense of Mass Supervision. Bingley: Emerald Publishing Limited.

Markley CW (1973) Furlough programs and conjugal visiting in adult correctional institutions. Federal Probation 37(1): 19-26.

Mathiesen T (1965) The Defences of the Weak: A Sociological Study of a Norwegian Correctional Institution. London: Tavistock Publications.

Monahan J and Skeem JL (2016) Risk assessment in criminal sentencing. Annual Review of Clinical Psychology 12: 489-513.

Povoroznyy v. Ukraine (2020) European Court of Human Rights case No. 5276/13. URL (accessed 7 September 2020): http://hudoc.echr.coe.int/eng?i=001-202617.

Prison Bylaws (Verbatim: Rules of Internal Regimentation of Criminal-Executive Establishments) (2018) Ministry of Justice Order No 2823/5, 28.08.2018. URL (accessed 7 September 2020): http://zakon.rada.gov.ua/laws/show/z1010-18.

Prison Portal of Donetsk Memorial (2020) The Ukrainian criminal-executive system in 2019. A statistical overview. URL (accessed 7 September 2020): http://ukrprison.org.ua/articles/1581323348.

Shammas VL (2014) The pains of freedom: Assessing the ambiguity of Scandinavian penal exceptionalism on Norway's Prison Island. Punishment and Society 16(1): 104-123.

Shichor D and Allen HE (1978) Study-release. Offender Rehabilitation 2(1): 7-17.

Singh JP and Fazel S (2010) Forensic risk assessment. Criminal Justice and Behavior 37(9): 965-988.

Subcommittee on Prevention of Torture and other Cruel, Inhuman or Degrading Treatment or Punishment (2006) Consideration of reports submitted by States parties under Article 19 of the Convention: fifth periodic reports of States parties due in 2004 - Ukraine. Addendum. CAT/C/81/Add.1, 17 October 2006. URL (accessed 7 September 2020): https://tbinternet. ohchr.org/_layouts/15/treatybodyexternal/Download.aspx?symbolno=CAT\%2fC $\% 2 \mathrm{f} 81 \% 2 \mathrm{f}$ Add.1\&Lang=en.

Subcommittee on Prevention of Torture and other Cruel, Inhuman or Degrading Treatment or Punishment (2007) Summary record of the 765th meeting: Ukraine. CAT/C/SR.765, 21 May 2007. URL (accessed 7 September 2020): https://tbinternet.ohchr.org/_layouts/15/treatybodyexternal/Download.aspx?symbolno=CAT\%2fC\%2fSR.765\&Lang=en.

Subcommittee on Prevention of Torture and other Cruel, Inhuman or Degrading Treatment or Punishment (2014) Concluding observations on the sixth periodic report of Ukraine. CAT/C/ UKR/CO/6, 12 December 2014. URL (accessed 7 September 2020): http://tbinternet.ohchr. org/_layouts/treatybodyexternal/Download.aspx?symbolno=CAT/C/UKR/CO/6\&Lang=En.

Subcommittee on Prevention of Torture and other Cruel, Inhuman or Degrading Treatment or Punishment (2017) Visit to Ukraine undertaken from 19 to 25 May and from 5 to 9 September 2016: observations and recommendations addressed to the State party. CAT/OP/UKR/3, 18 May 2017. URL (accessed 7 September 2020): http://tbinternet.ohchr.org/_layouts/treatybodyexternal/Download.aspx?symbolno=CAT\%2FOP\%2FUKR\%2F3\&Lang=en.

Sykes GM (1958) The Society of Captives: A Study of a Maximum Security Prison. Princeton, NJ: Princeton University Press. 
Symkovych A (2017) Sex in prisoner power relations: Attitudes and practices in a Ukrainian correctional colony for men. Howard Journal of Crime and Justice 56(1): 1-18.

Symkovych A (2018a) Compromised power and negotiated order in a Ukrainian prison. British Journal of Criminology 58(1): 200-217.

Symkovych A (2018b) Do men in prison have nothing to lose but their manhood? Masculinities of prisoners and officers in a Ukrainian correctional colony. Men and Masculinities 21(5): 665-686.

Symkovych A (2018c) The 'inmate code' in flux: A normative system and extralegal governance in a Ukrainian prison. Current Sociology 66(7): 1087-1105.

Symkovych A (2018d) The Ukrainian response to Sykes: Prisoner hierarchy and self-rule - power, legitimacy, and dynamics. British Journal of Criminology 58(5): 1087-1106.

Symkovych A (2019) The legal and illegal use of force by prison officers in Ukraine. Prison Journal 99(1): 89-111.

Symkovych A (2020a) Negative visibility and 'the defences of the weak': The interplay of a managerial culture and prisoner resistance. Theoretical Criminology 24(2): 202-221.

Symkovych A (2020b) The eye of a needle: Temporary prison leave in Ukraine. European Journal on Criminal Policy and Research 26(2): 195-210.

Toch H (1967) Prison inmates' reactions to furlough. Journal of Research in Crime and Delinquency 4(2): 248-262.

Turnbull S and Hannah-Moffat K (2009) Under these conditions: Gender, parole and the governance of reintegration. British Journal of Criminology 49(4): 532-551.

Turner S and Petersilia J (1996) Work release in Washington: Effects on recidivism and corrections costs. Prison Journal 76(2): 138-164.

Ugelvik T (2014) Power and Resistance in Prison: Doing Time, Doing Freedom. London: Palgrave.

Ukrainian Penitentiary Service (2020) General features of the State Criminal-Executive Service of Ukraine. URL (accessed 10 July 2020): https://kvs.gov.ua/wp-content/uploads/2020/06/ Загальна-характеристика-01.06.2020.pdf.

United Nations (2015) United Nations Standard Minimum Rules for the Treatment of Prisoners (the Nelson Mandela Rules). A/RES/70/175. URL (accessed 7 September 2020): https:// undocs.org/A/RES/70/175.

Vieraitis LM, Kovandzic TV and Marvell TB (2007) The criminogenic effects of imprisonment: Evidence from state panel data. Criminology and Public Policy 6(3): 589-622.

Waldo GP and Chiricos TG (1977) Work release and recidivism: An empirical evaluation of a social policy. Evaluation Review 1(1): 87-108.

Warr J (2020) 'Always gotta be two mans': Lifers, risk, rehabilitation, and narrative labour. Punishment and Society 22(1): 28-47.

Wright KA and Rosky JW (2011) Too early is too soon: Lessons from the Montana Department of Corrections early release program. Criminology and Public Policy 10(4): 881-908. 


\section{University Library}

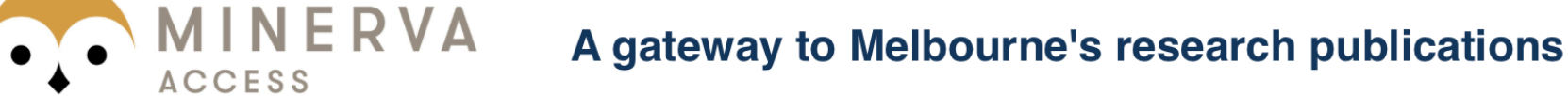

Minerva Access is the Institutional Repository of The University of Melbourne

Author/s:

Symkovych, A

Title:

Untrustworthy subjects? Risks, blame and gradual prison release in Ukraine

Date:

2022-09

Citation:

Symkovych, A. (2022). Untrustworthy subjects? Risks, blame and gradual prison release in Ukraine. European Journal of Criminology, 19 (5), pp.1225-1242. https:// doi.org/10.1177/1477370820960613.

Persistent Link:

http://hdl.handle.net/11343/252224

License:

cc-by-nc 